\title{
TRANSIENT THERMAL ANALYSIS OF PHASE CHANGE MATERIAL BASED HEAT SINKS
}

\author{
Azeem Anzar ${ }^{1}$, Shine $\mathbf{K}^{2}$ \\ ${ }^{I}$ Mechanical Engineering Department, MES College of Engineering, Kuttipuram, Kerala, India \\ ${ }^{2}$ Assistant Professor,Mechanical Engineering Department, MES College of Engineering, Kuttipuram, Kerala, India \\ azeemrainbow@gmail.com, shinekunnath@gmail.com
}

\begin{abstract}
Integrated circuits operate best in a limited range of temperature hence their package must be designed to remove the excessive heat. As an alternative passive cooling technique means, phase change materials or PCMs have been widely investigated for such transient cooling applications considering their advantage such as high latent heat of fusion, high specific heat, controllable temperature stability and small volume change during phase change, etc. This PCM based cooling techniques have great potential application in the devices which are not operated continuously over a long period, but in intermittently using devices like cellular phones, digital cameras, notebook etc. The PCM absorbs heat from the electronic component when it operates and melts, the molten PCM needs to be re-solidified by dissipating heat to the surroundings while the electronic device are idle, such a cooling system is applicable only for intermittent use devices and not those in continuous operation. To achieve effective cooling it is important to ensure that the operating duration of the electronic device does not exceed the time of full melting of PCM. Advanced transient analysis is required for clear understanding of the mechanism behind this method of cooling while practical implementations are considered. Controlled convective cooling techniques can be implemented for continuous operation such kind of systems.
\end{abstract}

The present work is a numerical study consists of thermal analysis of various configurations of finned heat sink with PCM. The configurations considered are finned heat sink without PCM and with PCM, Half-filled PCM towards the fin tip side and cases which includes forced convection for systems with continuous operation.

The unsteady analyses were performed to record the transient nature of problem. The characteristic of PCM and the design of operational time of convective cooling are estimated. By analyzing these different configurations a vivid picture of the physics of heat transfer in PCM based heat sink is figured out.

Keywords: Phase change materials; Heatsink; electronics cooling; Thermal management

\section{INTRODUCTION}

Technological enhancements at the device, package and system levels have resulted in increased functionality and decreased form factors, but squeezed more power into ever-small packages. As a consequence, thermal management has become more critical for successful design of electronic devices such as cellular phones, digital cameras, notebooksand personal digital assistants, etc. Such devices are not operated continuously over long periods, so a phase change material (PCM)-based cooling system haspotential for application. Integrated circuits operate bestwithin a limited temperature range; hence their packagesmust be designed to remove the excessive heat. As an alternative passive cooling technique means, PCMs have beenwidely investigated for such transient electronic coolingapplications considering their advantages such as highlatent heat of fusion, high specific heat, controllable temperature stability and small volume change during phase change, etc.
The phase change materials (PCMs) are heat storage mediums used in latent heat storage, as it will experience a phase transition during the heat charge or release process. Theoretically, PCM has a phase change point when the phase transition happens, but in practice the phase change process happens in a certain temperature range instead of one exact point.

Based on the phase change process, PCMs can be classified into solid-liquid, liquid-gas andsolid-solid PCM. Among these three types of PCM: solid-solid PCM is rarely suitable for the thermal storage in buildings; liquid-gas PCM experiences a very significant volume change due to the difference of molecular intervals between the gas and liquid; thus, in general only solidliquid PCM is suitable for the normal applications. Currently, there are mainly three types of PCMs existing in the solid-liquid category: organic-PCM,inorganic-PCM and eutectic-PCM, each of which can be further categorized into more detailed subgroups 
PCM based cooling system can be implemented in conditions where devices which are not operated continuously over a long period, but in intermittently using devices like cellular phones, digital cameras, notebook etc

The PCM absorbs heat from the electronic component when it operates and melts, the molten PCM needs to be re-solidified by dissipating heat tothe surroundings while the electronic device are idle, such a cooling system is applicable only for intermittent use devices and not those incontinuous operation. Forced convection cooling with fins are common method for cooling of chips which are in continuous operation.

\section{LITERATURE REVIEW}

V. Shatikian, G. Ziskind and R. Letan "Heat accumulation in a PCM-based heat sink with internal fins" In this paper the processes of melting of a phase-change material (PCM), in a heat sink with a constant-heat-flux horizontal base and vertical internal plate fins, have been studied numerically. A most complete formulation has been attempted, which takes into account conduction inside the fins, conduction and convection in the PCM, volume change of the PCM associated with phase transition, density and viscosity variation in liquid PCM, and heat transfer to the surroundings. In a detailed parametric investigation, the results have illustrated how the heat accumulation due to the latent heat storage is affected by the changes in the geometry of the system and the boundary conditions. The results of these problems show the predominant role of fins in transferring heat to the PCM. The approach developed herein can be used in the design of PCM-based cooling systems.

V. Dubovsky, E. Assis, E. Kochavi, G. Ziskind and R. Letan "study of solidification in vertical cylindrical shells" This paper the process of solidification of a phase change material (PCM) in cylindrical geometry has been explored numerically. Transient numerical simulations were performed using Fluent 6.2. Solidification temperature of the PCM was incorporated in the simulations along with its other properties, including the latent and sensible specific heat, thermal conductivity and density in solid and liquid states. The simulations provided detailed phase distributions. To the best of our knowledge, some inherent features of the process have been modeled for the first time, including the curvilinear interface. An initial dimensional analysis of the results was attempted and presented as the PCM melt fractions vs. the Fourier and Stefan numbers. A generalization, which encompasses the cases considered herein, is suggested. A detailed dimensional analysis will be done in a future study.

Gong and Arun S. Mujumadar “ A transient cooling of electronics using phase change materials "In this paper a well designed PCM based heat sink for various power levels was investigated experimentally and numerically. Results show that the inclusion of PCM in the cavities of the heat sinks will increases the cooling performance as compared to the cases without involved PCM when the input power level is relatively high. It carried out a series of numerical studies on heat transfer during melting and freezing of single and multiple PCMs. A new design for thermal storage using multiple PCMs was first proposed by them for power generation in space-based activities [1]. They extended their analysis from only the charge process (melting) to a combined charge/discharge (melting/ freezing) process [2].In [4], by a thermodynamic analysis, Gong and Mujumdar found that the increase of the overall thermal efficiency could theoretically be doubled, or even tripled by use of multiple PCMs.

Bogdan M. Diaconu,SzabolcsVargaand Armando C. Oliveira "Experimental assessment of heat storage properties and heat transfercharacteristics of a phase change material slurry for air conditioning applications"In this paper Possible applications of the microencapsulated PCM slurryinvestigatedin this paper include cold storage for air conditioningsystems with intermittent energy supply such as solar-driven airconditioning systems . Low temperature energy storage (cold storage) is an alternative to high temperature energy storage ensuring the cooling demand during intervals when energy supply(solar energy in this case) is not available.

$X$. Duan and G.F. Naterer "Heat transfer in phase change materials for thermal management of electric vehicle battery modules"In this paper, thermal management with phase change materials was investigated for their feasibility and effectiveness for electric vehicle battery modules. Detailed solidification and melting processes were examined and new measured PCM data was reported. In the experiments, a heater was used to simulate a battery cell. Two different PCM designs for the heater temperature management were investigated: one with a PCM container surrounding the heater, and another with a PCM jacket wrapping the heater. It was shown that both designs are effective in maintaining the heater temperature within a defined range. The effects of variable heating rates and ambient temperature conditions were also reported.

QIU Yifen, JIANG Nan, WU Wei, ZHANG Guangwei and XIAO Baoliang " Heat Transfer of Heat Sinking Vest with Phase-change material" This paper develops a heat transfer mathematical model about heat sinking vest with PCM by enthalpy method. This model can analyze the heat transfer process and calculate the skin heat flow covered with this vest. On the basis of the human thermo regulation model, dynamic temperature distribution and sweat rate of the body wearing the vest are solved.. In addition, dynamic temperature distribution and sweat rate comparison that body wears the vest or not show that this vest with PCM can reduce body heat load significantly. The heat transfer mathematical model with phase change built above is reasonable and reliable, and it can be used to research thermal protection performance of the heat sinking vest with PCM. 


\section{PHYSICAL MODEL}

The problem defined consists of finned heat sink geometry. The domain is simplified by imposing periodic boundary condition in order to reduce the grid size. The work is progressed in such a way that the performance fin computed by several situations such as fin only, fin filled with PCM material, fin filled with half-filled PCM and half-filled PCM based fin with forced convection.

The geometry of heat sink for different configuration used in this study. The fin only case, fin fully filed with pcm and fin half filled with pcm are included.

Case-1 Fin only

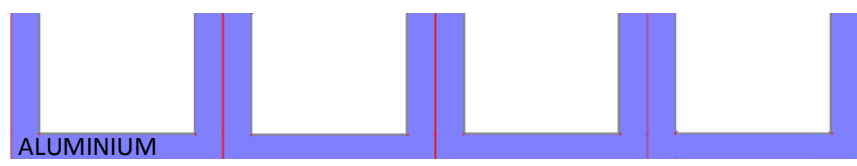

Case 2 Fin fully filled with PCM

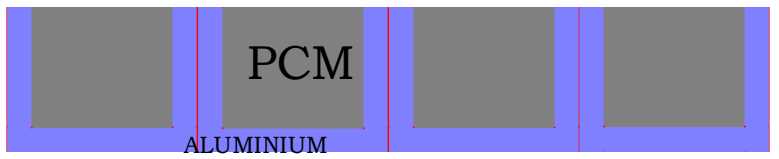

Case 2 Fin half- filled with PCM
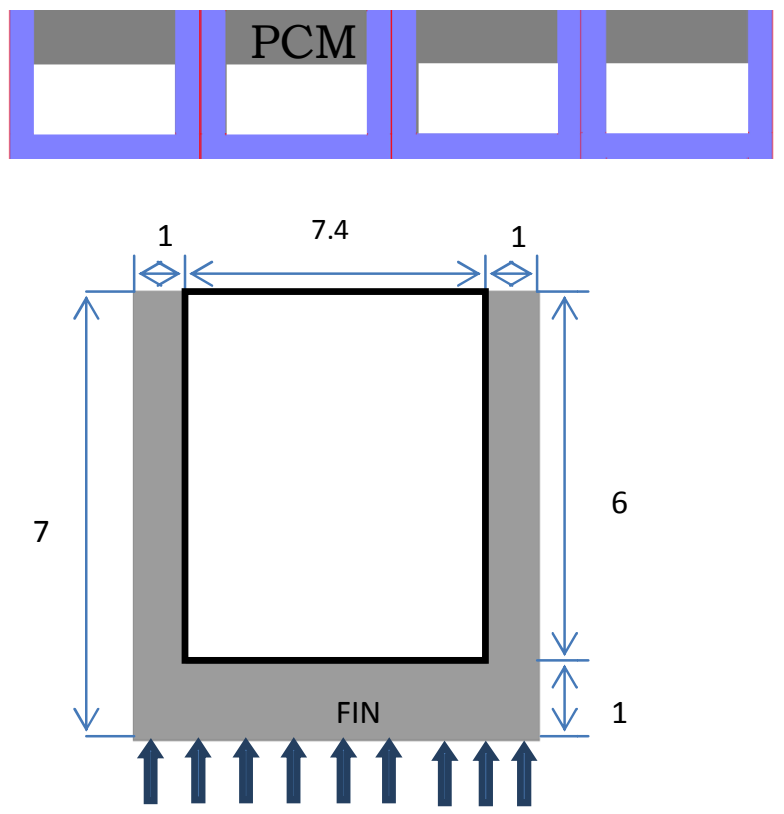

2Wheat

All dimensions are in $\mathrm{mm}$

Translational periodic model of heat sink configuration for forced convection cases.
The figureshows the dimensions of the geometry considered for this study.The all the length presented is in $\mathrm{mm}$. The thickness of fin considered in $2.7 \mathrm{~mm}$ and translational periodic condition is applied to mid plane of the fin. Three dimensional study is conducted only for the forced convection cases.

\subsection{Boundary Condition}

Boundary conditions include heat flux value of $200 \mathrm{~W} / \mathrm{m}^{2}$ applied at bottom of PCM for 3500s heating and 3500s cooling. All other walls are treated as adiabatic shown in fig.4.1 above. The domain interface between PCM and air is considered as wall to avoid material transfer. The initial condition set for entire domain is $18^{0} \mathrm{C}$.

Heat flux: The bottom wall is provided with a heat flux of 200 $\mathrm{W} / \mathrm{m}^{2}$.

Translational periodicity: The domain is simplified by using translational periodic assumption. The left and right walls are selected as periodic and periodic shadow surfaces.

Adiabatic wall: The fin tip surface and upper surface of pcm are considered as insulated boundary by applying a heat flux value of zero.

Inlet air velocity: Different air inlet velocity conditions are applied for various cases.

Outflow boundary: The gauge pressure of zero bar is applied for out let boundary with a back temperature of atmospheric temperature.

\section{Initial condition}

An initial condition Temperature in the domain is set as $18^{\circ} \mathrm{C}$

\section{Material}

The fin material of aluminium, phase change material used is paraffin wax and air as fluid for convective cooling.

\section{Convergence settings}

Mass, momentum and energy equations are monitored and the solution is taken in such a way that the residuals are converged to a value less than $10^{-6}$.

\section{Grid Independence study}

Different configurations are used to get a grid independent solution. In the steady 2-D problem the temperature values are plotted for different grid configurations and a grid number of 12500 rectangular grid is selected for the further study. In the case of 3D problem the previously obtained 2-D grid is extruded along flow direction and discretization in the flow direction is also selected accordingly. A total number of hexahedral of 625000 element used for 3D analysis 


\section{MATHEMATICAL AND NUMERICAL MODELING}

\subsection{Numerical Simulation}

FLUENT can be used to solve fluid flow problems involving solidification and/or melting taking place at one temperature (e.g., in pure metals) or over a range of temperatures (e.g., in binary alloys). Instead of tracking the liquid-solid front explicitly, FLUENT uses an enthalpy-porosity formulation. The liquid-solid mushy zone is treated as a porous zone with porosity equal to the liquid fraction, and appropriate momentum sink terms are added to the momentum equations to account for the pressure drop caused by the presence of solid material. Sinks are also added to the turbulence equations to account for reduced porosity in the solid regions. FLUENT uses control volume approach to solve fluid flow problems. In finite volume method, flow domain is discretized into cells and analysis is done by solving the governing equations on control points on cells. The finite volume method represents and evaluates partial differential equations as algebraic equations.

The instantaneous continuity equation, momentum equation and energy equation for a compressible fluid can be written as:

Continuity Equation:

$$
\frac{\partial \rho}{\partial t}+\frac{\partial}{\partial x_{j}}\left[\rho u_{j}\right]=0
$$

Momentum equation

$$
\frac{\partial}{\partial t}\left(\rho u_{i}\right)+\frac{\partial}{\partial x_{j}}\left[\rho u_{i} u_{j}+p \delta_{i j}-\tau_{j i}\right]=0
$$

Energy equation

$$
\frac{\partial}{\partial t}\left(\rho e_{0}\right)+\frac{\partial}{\partial x_{j}}\left[\rho u_{j} e_{0}+u_{j} p+q_{j}-u_{i} \tau_{i j}\right]=0 \ldots . .3(\mathrm{c})
$$

For a Newtonian fluid, assuming Stokes Law for mono-atomic gases, the viscous stress is given by

$$
\tau_{i j}=2 \mu S_{i j}
$$

Where the trace-less viscous strain-rate is defined by

$$
S_{i j}=\frac{1}{2}\left(\frac{\partial u_{i}}{\partial x_{j}}+\frac{\partial u_{j}}{\partial x_{i}}\right)-\frac{1}{3} \frac{\partial u_{k}}{\partial x_{k}} \delta_{i j}
$$

The heat-flux, $\mathrm{q}_{\mathrm{j}}$, is given by Fourier's law:

$$
q_{j}=-\lambda \frac{\partial T}{\partial x_{j}}=-C_{p} \frac{\mu}{P r} \frac{\partial T}{\partial x_{j}}
$$

Where the laminar Prandtl number Pris defined by:

$$
\operatorname{Pr}=\frac{C_{p} \mu}{\lambda}
$$

To close these equations it is also necessary to specify an equation of state. Assuming a calorically perfect gas the following relations are valid:

$$
\gamma=\frac{C_{p}}{C_{v}}, \mathrm{P}=\rho \mathrm{RT}, \mathrm{e}=\mathrm{C}_{\mathrm{v}} \mathrm{T}, \mathrm{C}_{\mathrm{v}^{-}} \mathrm{C}_{\mathrm{p}}=\mathrm{R}
$$

Where $\gamma, \mathrm{C}_{\mathrm{v}}, \mathrm{C}_{\mathrm{p}}$ and $\mathrm{R}$ are constant.

The total energy $\mathrm{e}_{0}$ is defined by:

$$
e_{0}=e+\frac{U_{k} U_{k}}{2}
$$

\subsection{Favre Averaged Equations}

It is not possible to solve the instantaneous equations directly for most engineering applications. At the Reynolds numbers typically present in real cases these equations have very chaotic turbulent solutions, and it is necessary to model the influence of the smallest scales. Most turbulence models are based on onepoint averaging of the instantaneous equations. The averaging procedure will be described in the following sections.

Let $\phi$ be any dependent variable. It is convenient to define two different types of averaging of $\phi$ :

Classical time averaging (Reynolds averaging)

$$
\begin{array}{r}
\bar{\phi}=\frac{1}{\mathrm{~T}} \int \phi(\mathrm{t}) \mathrm{dt} \ldots \ldots \ldots \ldots \\
\phi^{\prime}=\phi-\bar{\phi}
\end{array}
$$

Density weighted time averaging (Favre averaging):

$$
\widetilde{\Phi}=\frac{\overline{\rho \Phi}}{\bar{\rho}}
$$

$$
\Phi^{\prime \prime}=\Phi-\widetilde{\Phi}
$$

Note that with the above definitions, $\overline{\phi^{\prime}}=0$ but $\overline{\boldsymbol{\phi}^{\prime \prime}} \neq \mathbf{0}$

$$
\text { And } \dot{\phi}^{\prime}=\text { obut } \varnothing \neq 0
$$

\subsection{Solidification Modeling}

FLUENT can be used to solve fluid flow problems involving solidification and/or melting taking place at one temperature (e.g., in pure metals) or over a range of temperatures (e.g., in binary alloys). Instead of tracking the liquid-solid front explicitly, FLUENT uses an enthalpy-porosity formulation. The liquid-solid mushy zone is treated as a porous zone with porosity equal to the liquid fraction, and appropriate momentum sink terms are added to the momentum equations to account for the pressure drop caused by the presence of solid material. Sinks are also added to the turbulence equations to account for reduced porosity in the solid regions. 
The enthalpy of the material is computed as the sum of the sensible enthalpy, $\mathrm{h}$, and the latent heat, $\Delta \mathrm{H}$ :

$$
H=h+\Delta H
$$

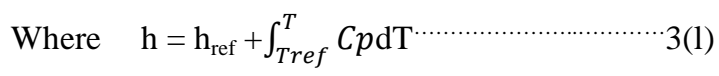

And $h_{\text {ref }}=$ reference enthalpy

$T_{\text {ref }}=$ reference temperature

$C p=$ specific heat at constant pressure

The liquid fraction, $\beta$, can be defined as

$$
\begin{gathered}
\beta=0 \text { ifT }<T_{\text {solidus }} \\
\beta=1 \text { ifT }<T_{\text {liquiduss }} \\
\beta=\frac{T-T_{\text {Solidus }}}{T_{\text {liquidus }}-T_{\text {Solidus }}} \text { if } T_{\text {solidus }}<T<T_{\text {liquidus }} \ldots . .3(\mathrm{~m})
\end{gathered}
$$

The latent heat content can now be written in terms of the latent heat of the material, $\mathrm{L}$ :

$$
\Delta H=\beta L
$$

Energy Equations

For solidification or melting problems, the energy equation is written as

$$
\frac{\partial}{\partial t}(\rho H)+\nabla \cdot(\rho \vec{v} H)=\nabla \cdot(k \nabla T)+S
$$

Where

$$
\begin{aligned}
& H=\text { enthalpy } \\
& \rho=\text { density } \\
& H=\text { enthalpy } \\
& \vec{V}=\text { Fluid velocity } \\
& \mathrm{S}=\text { source term }
\end{aligned}
$$

The solution for temperature is essentially iteration between the energy equations and the liquid fraction equation

The enthalpy-porosity technique treats the mushy region (partially solidified region) as a porous medium. The porosity in each cell is set equal to the liquid fraction in that cell. In fully solidified regions, the porosity is equal to zero, which extinguishes the velocities in these regions. The momentum sink due to the reduced porosity in the mushy zone takes the following form:

$$
S=\frac{(1-\beta)^{2}}{\left(\beta^{3}+\varepsilon\right)} A_{m u s h}(\vec{v})
$$

$\mathrm{S}=$ Momentum source term, $(\vec{v})=$ Fluid velocity
Default value of 100000 and 0.001 is used the constants $A_{\text {mush }}$ and $\varepsilon$ simultaneously

\subsection{Analysis Procedure}

The modeling of flow domain has been completed using geometry and mesh building software, GAMBIT. General sequence of operation involved is:

1) Create full geometry and decompose into mesh able sections.

2) Give meshes required.

3) Continuum and boundary attachment.

4) Export Mesh.

Analysis is done using FLUENT software. General sequence of operation involved is:

1) Importing grid.

2) Checking grid.

3) Setting units.

4) Define solver properties (steady, unsteady, 2D/3D etc).

5) Define Model (Solidification and heating, turbulent properties)

6) Define material properties (density, viscosity variation etc..).

7) Define operating conditions.

8) Define boundary conditions.

9) Initialization.

10) Setting convergence criteria.

11) Iterating until the solution converges.

\subsection{Fluent Settings}

Geometry is created using GAMBIT. Two dimensional model is created. Discretization is done by using mapped quad mesh with boundary layer on solid fluid interface. Gambit file is exported as .mesh format. The settings of ANSYS Fluent 14 for numerical solution are listed in this section. The discretized geometry is imported into Fluent. Fluent will perform various checks on the mesh and will report the progress in the console. It is needed to make sure that the minimum volume is a positive number. The imported grid is checked and proper scaling is done. The required units are selected.

General settings: The general settings such as solver settings, details of temporal discretization, properties of materials and equations required solving and additional physics required etc. are selected depend on the problem. Table listed shows the basic solver settings provided.

\begin{tabular}{|c|c|}
\hline Model & Settings \\
\hline Space & 2D/3D \\
\hline Solver & Pressure based \\
\hline Time & $\begin{array}{c}\text { Steady / Unsteady, 1st-Order } \\
\text { Implicit }\end{array}$ \\
\hline
\end{tabular}




\begin{tabular}{|c|l|}
\hline Viscous & Laminar \\
\hline Heat Transfer & Enabled \\
\hline $\begin{array}{c}\text { Solidification and } \\
\text { Melting }\end{array}$ & Enabled \\
\hline
\end{tabular}

Modeling Solidification: Solidification \& Melting is enabled in order to satisfy phase change conditions. The default value of 100000 selected for the mushy zone.

Material propertiesIn this step, a new material is created and specified its properties, including the melting heat, density, Specific heat, conductivity, viscosity, solidus temperature, and liquidus temperature. Aluminium material for fin, Paraffin wax as PCM material and air as forced convection fluid are taken. The settings provide for paraffin wax are given in the following Table. The Specific heat of PCM material is given as a piece wise continuous function of temperature. Material property of Paraffin

\begin{tabular}{|c|c|c|c|}
\hline Property & Units & Method & Value(s) \\
\hline Density & $\mathrm{kg} / \mathrm{m} 3$ & constant & $\begin{array}{c}834.3696 \\
9\end{array}$ \\
\hline $\begin{array}{c}\text { Cp } \\
\text { Specific } \\
\text { Heat) }\end{array}$ & $\mathrm{J} / \mathrm{kg}-\mathrm{K}$ & $\begin{array}{c}\text { Piece } \\
\text { wise } \\
\text { continuou } \\
\mathrm{s}\end{array}$ & - \\
\hline $\begin{array}{c}\text { Thermal } \\
\text { Conductivi } \\
\text { ty }\end{array}$ & $\mathrm{w} / \mathrm{m}-\mathrm{K}$ & constant & 0.22955 \\
\hline $\begin{array}{c}\text { Viscosity } \\
\text { Melting } \\
\text { Heat }\end{array}$ & $\mathrm{kg} / \mathrm{m}-\mathrm{s}$ & constant & .0080000004 \\
\hline $\begin{array}{c}\text { Solidus } \\
\text { Temperatu } \\
\text { re }\end{array}$ & ${ }^{\circ} \mathrm{C}$ & constant & 70006 \\
\hline $\begin{array}{c}\text { Liquidus } \\
\text { Temperatu } \\
\text { re }\end{array}$ & ${ }^{\circ} \mathrm{C}$ & constant & 26.99999 \\
\hline
\end{tabular}

\begin{tabular}{|c|l|l|l|l|l|l|}
\hline $\begin{array}{c}\text { Temp } \\
{ }^{\circ} \mathrm{C}\end{array}$ & 18 & 20 & 22 & 24 & 26 & 28 \\
\hline $\mathrm{Cp}$ & 5352 & 6400 & 7000 & 8067 & 5766 & 5042 \\
\hline $\begin{array}{c}\text { Temp } \\
{ }^{\circ} \mathrm{C}\end{array}$ & 30 & 32 & 34 & 36 & 38 & 40 \\
\hline $\mathrm{Cp}$ & 3808 & 3125 & 2998 & 2960 & 2922 & 2900 \\
\hline
\end{tabular}

\begin{tabular}{|l|c|l|c|}
\hline Property & Unit & Method & Value \\
\hline Density & $\mathrm{Kg} / \mathrm{m} 3$ & constant & 2719 \\
\hline $\mathrm{Cp}$ & $\mathrm{J} / \mathrm{kg} . \mathrm{K}$ & Constant & 871 \\
\hline Thermal & W/m.K & Constant & 202.4 \\
\hline
\end{tabular}

\begin{tabular}{|l|l|l|l|}
\hline Conductivity & & & \\
\hline
\end{tabular}

Material property of Aluminum

\subsection{Boundary Conditions}

Wall: Heat flux of $200 \mathrm{~W} / \mathrm{m}^{2}$ on the heater side of PCM and top wall as adiabatic. The solid-fluid interface is taken as coupled boundary.

Periodic surfaces: The translational periodic boundary is used to reduce the size of the problem. The periodic surface and shadow surface equally discretized in order to establish transitional periodicity.

Inlet boundary condition: The air inlet condition is used in the forced convection case in which the velocity and temperature of air inlet is specified.

Outlet boundary: The outlet pressure of atmospheric condition is provided.

Solver controls: The flow equations and energy equations are solved. The defaults under relaxation factors are taken. Pressure velocity coupling is done by SIMPLE algorithm. Pressure is discretized by using PRESTO scheme and momentum and energy by first order upwind scheme.

Solver initialization: In the unsteady analysis solutions are initialized from an initial temperature value of $18^{\circ} \mathrm{C}$. The convergence curve is plotted during the runtime by enabling residual plot and surface plot of temperature and liquid fraction of PCM with varying time.

\subsection{Grid Independence Study}

The structured grid used in this study has been obtained from a systematic grid sensitivity study in which the temperature in different locations for 2D case and temperature and mass flow rate has been compared.

\section{Convergence}

The criterion for assessing convergence of the present steady state analysis is based on the square root of sum of squares of temporal variation of variable such as density, velocity, temperature etc.

$$
R(\zeta)=\left[\sum_{i=1}^{N}\left(\frac{\partial \zeta}{\partial t}\right)_{i}^{2}\right]^{\frac{1}{2}}
$$

Where $\mathrm{N}$ is the number of grid points and $\zeta$ is the variable considered. Generally, computations are stopped when residues fall below $10^{-6}$. 
In addition to this the mass imbalance is also checked in the same manner.

$$
\left|\frac{\sum m_{\text {in }}-\sum m_{\text {out }}}{\sum m_{\text {in }}}\right| \leq 10^{-5}
$$

Where $\mathrm{m}_{\text {in }}$ is the mass fluid entering the domain and $\mathrm{m}_{\text {out }}$ is the mass fluid leaving the domain.

\section{RESULTS AND DISCUSSION}

\subsection{Introduction}

The result from the different analysis is reported in this chapter. The various cases such as fin only, fin fully filled with PCM, half-filled fin with forced convection etc. are reported one by one. The characteristics of PCM on heating and cooling are analysed and discussed. The cases with different velocity boundary conditions are compared and a strategy of intermittent use of convective heat transfer is established. The geometry, grid, boundary conditions and numerical settings adopted etc. are discussed in previous chapters. The results are presented in the form of contours of temperature, liquid fraction and heat transfer coefficient.

$$
\text { Heat sink with fin only }
$$

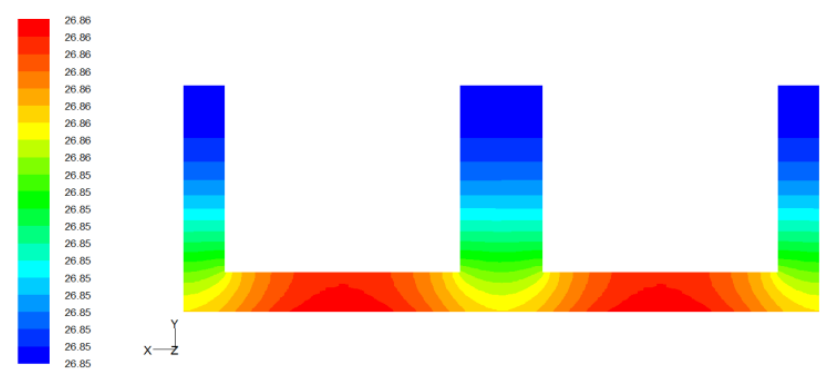

Temperature $\left({ }^{\circ} \mathrm{C}\right)$ contour at $300 \mathrm{~s}$ time

In this case an unsteady simulation is carried out. The temperature contour at $300 \mathrm{~s}$ is shown in the figure 5.1. The maximum temperature along the heat sink with time is plotted in the figure. Since the walls are adiabatic the supplied heat flux increases the temperature linearly. From the temperature contour it is clearly visible that the isothermal lines are perpendicular with the adiabatic walls. A temperature increase in the rate of 0.03 unit.

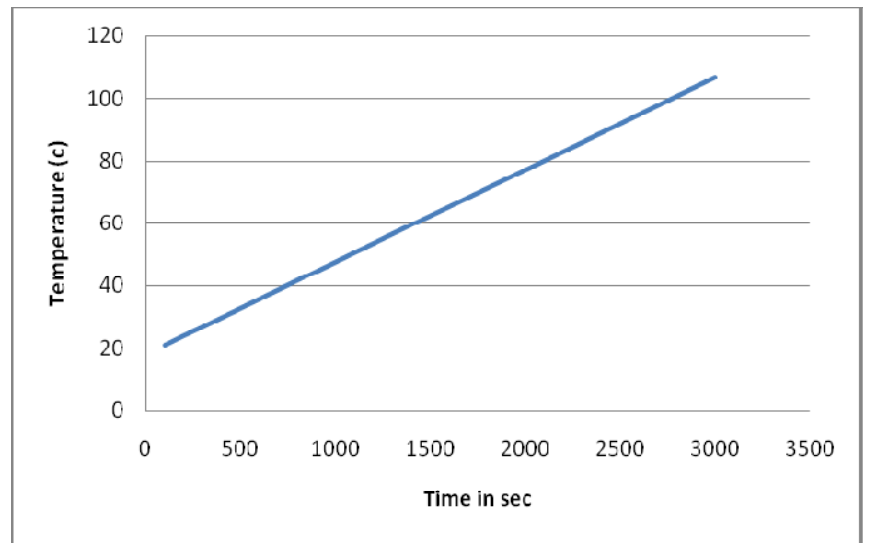

Temperature $\left({ }^{\circ} \mathrm{C}\right)$ Vs Time $(\mathrm{sec})$

\subsection{Heat Sink with Fin Fully Filled with PCM}

In this case an unsteady analysis is carried out for the heat sink with fully filled PCM. Boundary conditions include heat flux value of $200 \mathrm{~W} / \mathrm{m}^{2}$ applied at bottom of PCM for 3500 s heating and 3500s cooling. All other walls are treated as adiabatic walls. Domain interface between PCM and air is considered as wall to avoid material transfer. The initial condition set for entire domain is $18^{0} \mathrm{C}$.

The time at which entire PCM becomes liquid is find out (liquid fraction becomes one). The cooling is also studied by implementing reversing of heat flux direction. The temperature characteristics at various location of the computational domain is studied. The characteristics on PCM material on cooling and heating process is analyzed. It can be seen that for a time of 53 minute the temperature of the domain can be controlled by PCM. At around $3200 \mathrm{sec}$ the entire PCM becomes melted and further accommodation of heat in the PCM is restricted. After that period the domain temperature increases linearly.

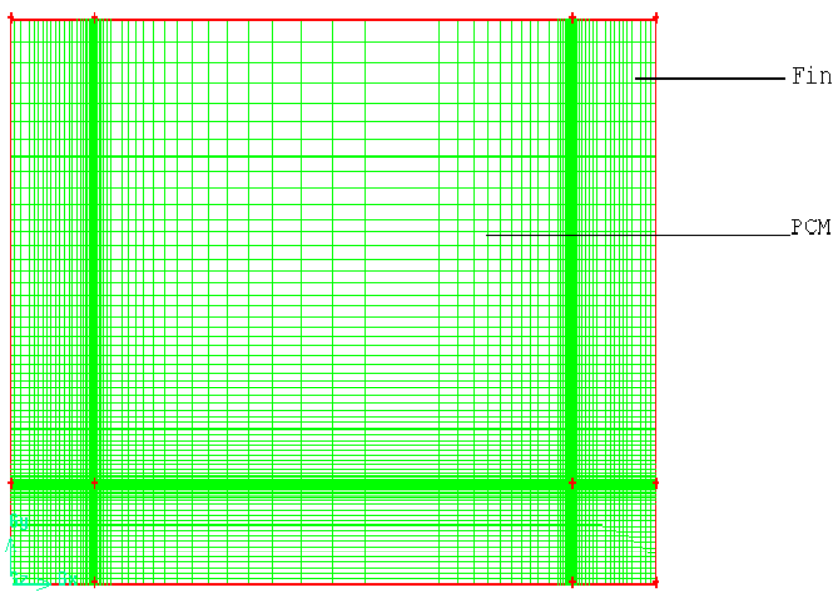

Grid used for fin with fully filled pcm 


\subsection{Maximum Temperature Change With Time}

The below figure shows the temperature verses time graph in both heating and cooling step for different locations P, P2, and $\mathrm{P} 3$ as in the figure.

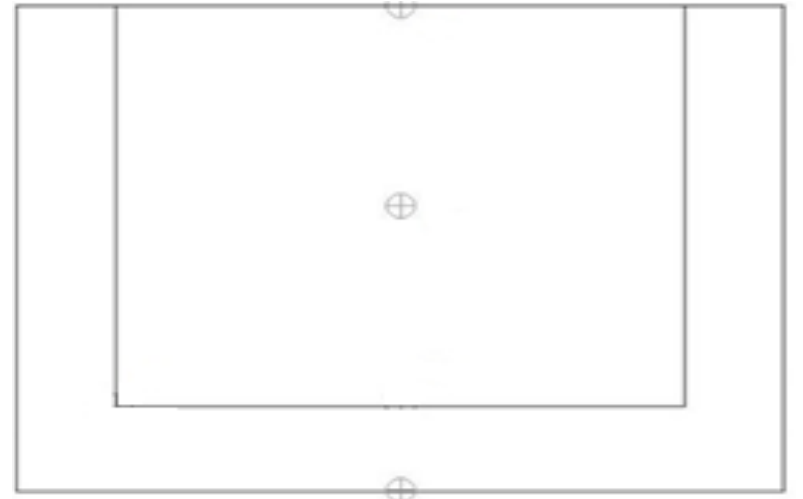

The different location selected for temperature comparison

The figure shows the temperature variation with time for different locations as mentioned in figure The variation in the slop indicates the presence of PCM up to $3200 \mathrm{sec}$. The specific heat of PCM various with temperature, hence at time above 100s the PCM start phase change and which is having large heat storage capacity. After complication of the phase transformation the heat storage capacity becomes linear in nature. In the cooling process the pcm material releases heat energy and transformed into solid phase.

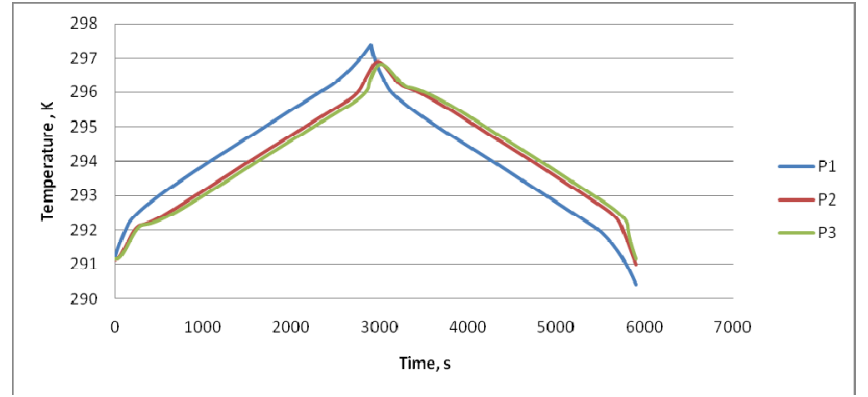

Temperature variation with time for different locations considered

\section{Contours of Temperature at various $\mathrm{T} 1$}

Figure shows the contours of temperature and liquid fraction at $500 \mathrm{sec}$ in the fin with fully filled PCM configuration. The PCM in solid face started liquefying near the interface region. The corner portion liquid for because of the large interface area in the corner region. The temperature contour is seems to be perpendicular to the top wall of the pcm, indicate an insulated boundary condition. The maximum temperature reaches at $19.1^{\circ} \mathrm{C}$ at $500 \mathrm{sec}$.
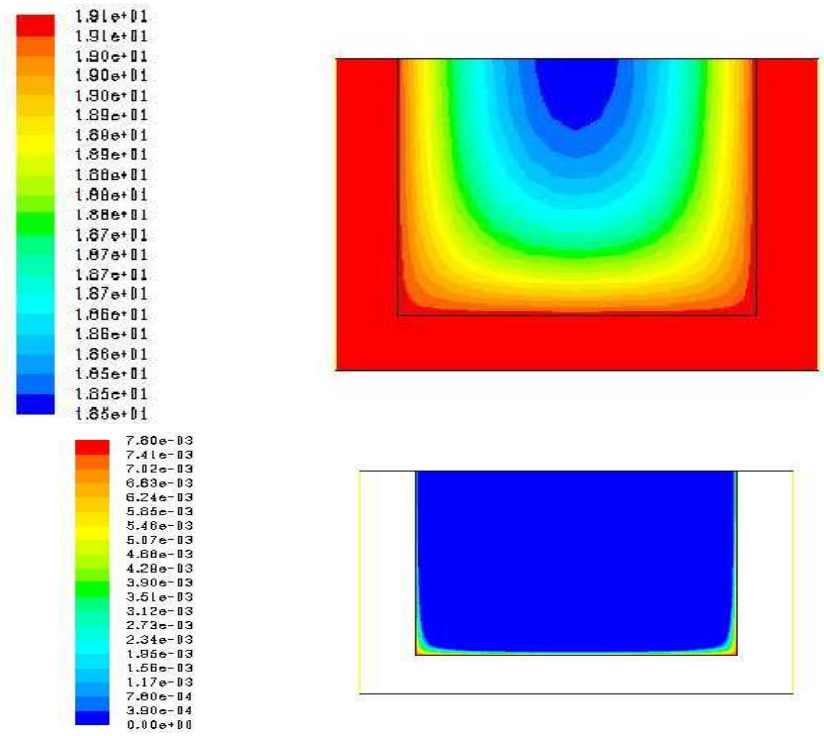

Figure. Contours of temperature and liquid fraction at $500 \mathrm{sec}$

Figure shows the contours of temperature and liquid fraction at $2200 \mathrm{sec}$ in the fin with fully filled pcm configuration. Above $50 \%$ volume of pcm is having a liquid fraction more than 0.5 . The maximum temperature reaches at $22.6^{\circ} \mathrm{C}$ at $2200 \mathrm{sec}$.

\begin{tabular}{|c|c|}
\hline Base of fin & P1 \\
\hline $\begin{array}{c}\text { Geometric centre of } \\
\text { PCM }\end{array}$ & P2 \\
\hline Top of PCM & P3 \\
\hline
\end{tabular}
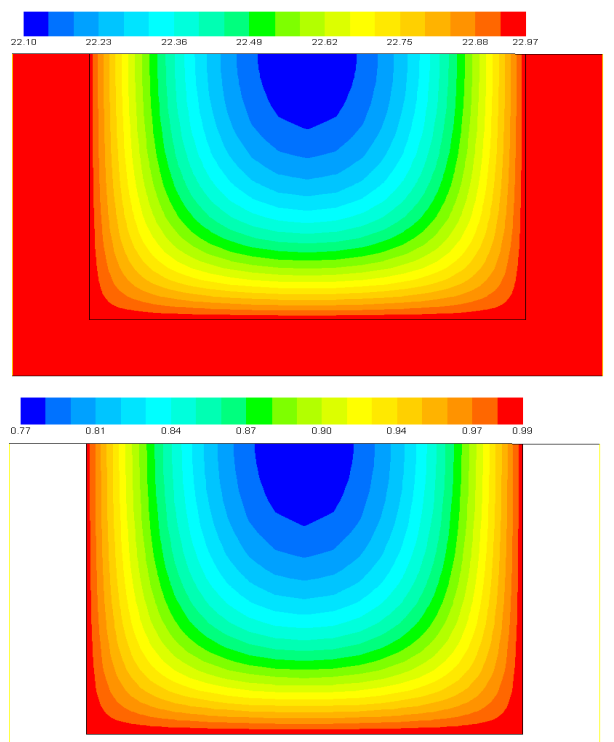

Contours of temperature and liquid fraction at $2200 \mathrm{sec}$ 
Figure shows the contours of temperature and liquid fraction at $3500 \mathrm{sec}$ in the fin with fully filled pcm configuration. It can be seen that the minimum temperature in the pcm domain is $25.2^{0} \mathrm{C}$ (above themelting limit) and hence the entire portion of pcm is converted in to liquid and at/after that the variation in the temperature of system changed linearly.
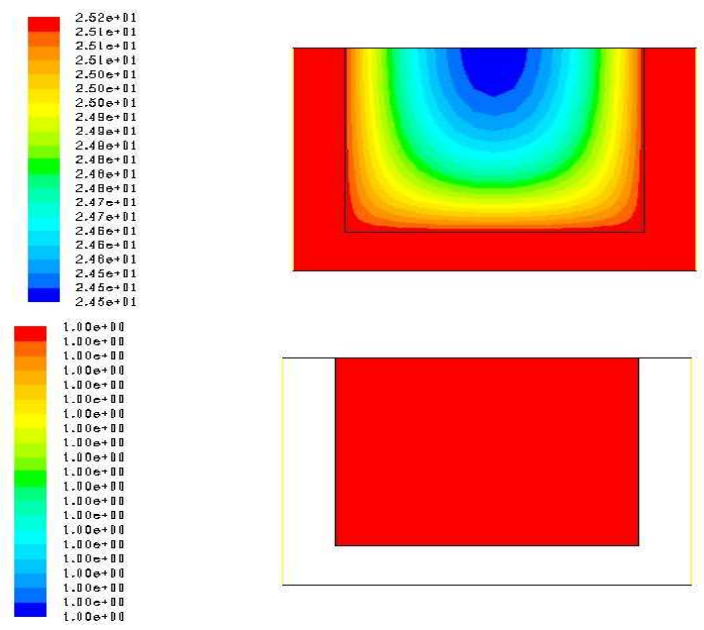

Contours of temperature and liquid fraction at $3500 \mathrm{sec}$

\subsection{Heat Sink With Fin Half Filled With PCM}

In this section the result of half- filled PCM with forced convection is studied. The Three-dimensional domain is created. The figure shows the transitional periodic model of grid used in this study.

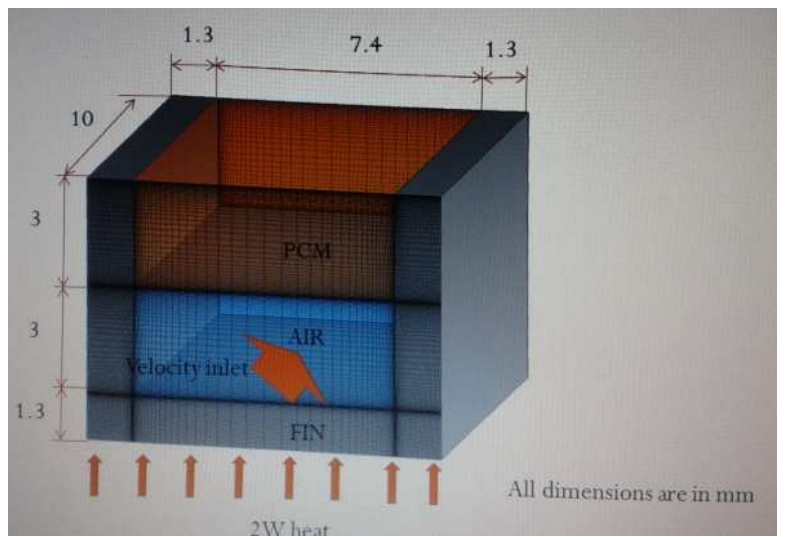

Computational domain used for half-filled PCM with forced convection

The Figure shows the velocity vector in a cross-sectional plane for a inlet air velocity of $0 \mathrm{~m} / \mathrm{s}$. It can be seen that there is a natural convection phenomena. The flow direction shows two major loop which meets at the central of the domain with high velocity magnitude. There exist four small loops along the corner portion of the plane. The maximum velocity of air reached at about $0.15 \mathrm{~m} / \mathrm{s}$ due to buoyant force
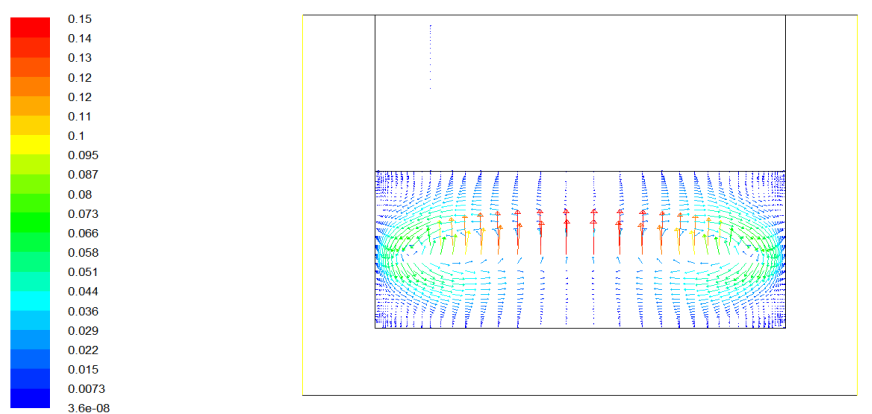

Vector of the cross-section on air flow for an inlet velocity of zero

The velocity vector on the cross section of air flow domain depictured in figure shows two recirculation loops. A temperature driven maximum velocity of $0.14 \mathrm{~m} / \mathrm{s}$ is obtained in the flow.

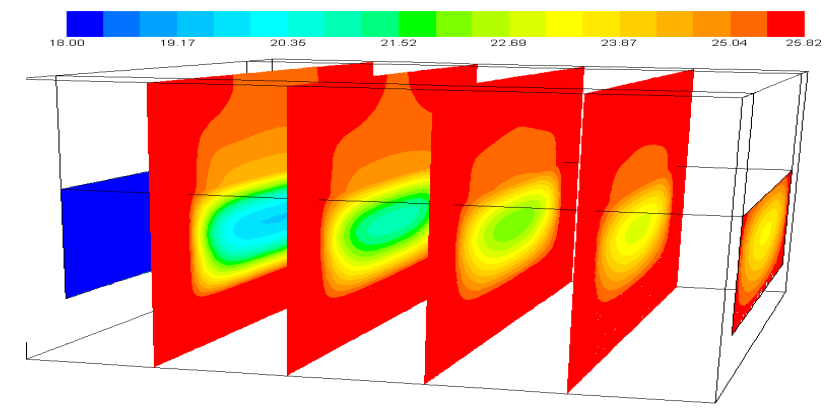

a. Air inlet velocity $=10 \mathrm{~cm} / \mathrm{s}$

Temperature contour at locations of inlet, 2,4,6,8 $\mathrm{mm}$ from inlet, outlet plane

In the case of forced convection flow, steady analysis is carried out for an inlet velocity of $0.1 \mathrm{~m} / \mathrm{s}-2 \mathrm{~m} / \mathrm{s}$. The Figure shows the temperature and liquid fraction for various inlet velocity at different axial locations such as 2,4,6, $8 \mathrm{~mm}$ from inlet and inlet and outlet boundary. It can be seen that the air becomes hot as it flow through the path. The maximum temperature is reduced as the flow velocity increases. 


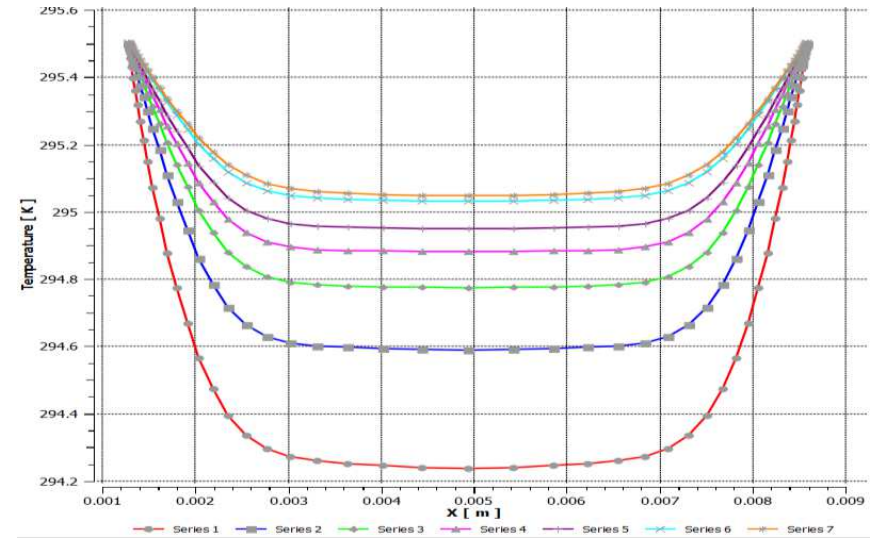

Temperature at the interface between air and PCM at different axial location 1,2,3,4,5,6,7 $\mathrm{mm}$ from inlet for air velocity of $10 \mathrm{~cm} / \mathrm{sat} 7 \mathrm{~mm}$ from the inlet.

Figure shows the temperature plot at the interface region of air and $\mathrm{pcm}$ at various axial locations series 1 from $1 \mathrm{~mm}$ from the inlet and series7 locations. Heat transfer is maximum at the inlet region of the flow. In the figure 5.12 mass flow averaged temperature of the outlet for different velocity is plotted. It can be seen that the increasing of velocity above $1.5 \mathrm{~m} / \mathrm{s}$ doesn't aid any further temperature reduction in the system. The liquid fraction vs velocity plotted in the figure 5.13 also prove this point. The change in liquid fraction with velocity is less in the velocity range above $1.5 \mathrm{~m} / \mathrm{s}$.

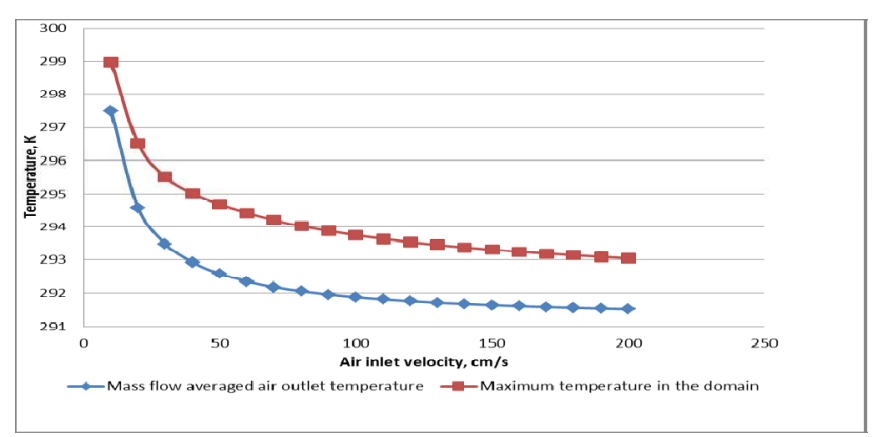

Mass flow averaged and maximum temperature in the domain for different axial velocities

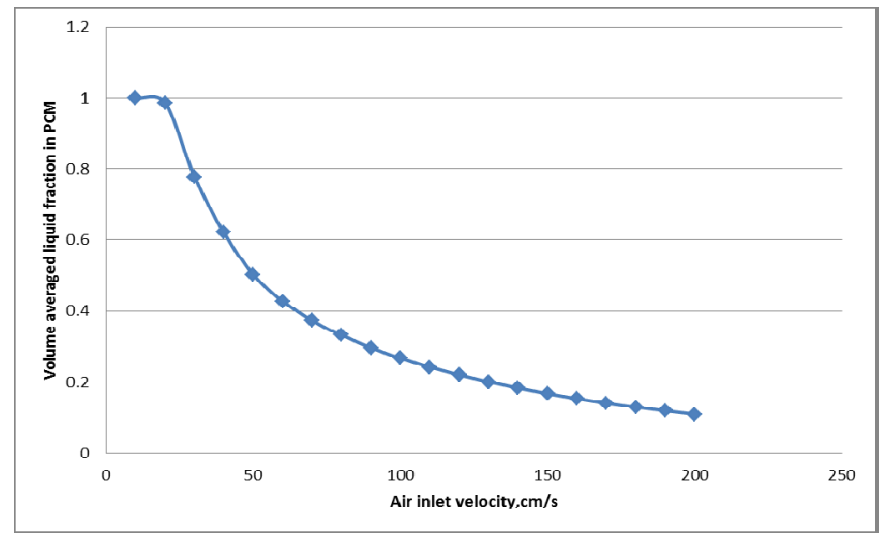

b. Air inlet velocity $=150 \mathrm{~cm} / \mathrm{s}$

Volume averaged liquid fraction for different axial velocities

The unsteady analysis is done for different velocity inlets. Firstly the analysis is carried out for a time up to volume averaged liquid fraction of one with zero velocity inlet. Later different analyses for different velocities are carried out by using the first result. Figure 5.14 and 5.15 shows minimum domain temperature and liquid fraction of PCM along the time. The effect air velocity up to $0.2 \mathrm{~m} / \mathrm{s}$ is negligible and further increase in velocity stabilizes liquid fraction and temperature.

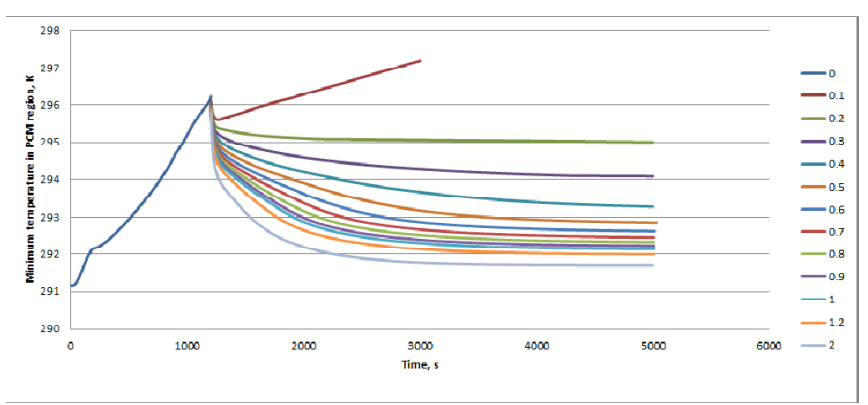

Minimum temperature in PCM region with time for different inlet velocity $(\mathrm{m} / \mathrm{s})$.

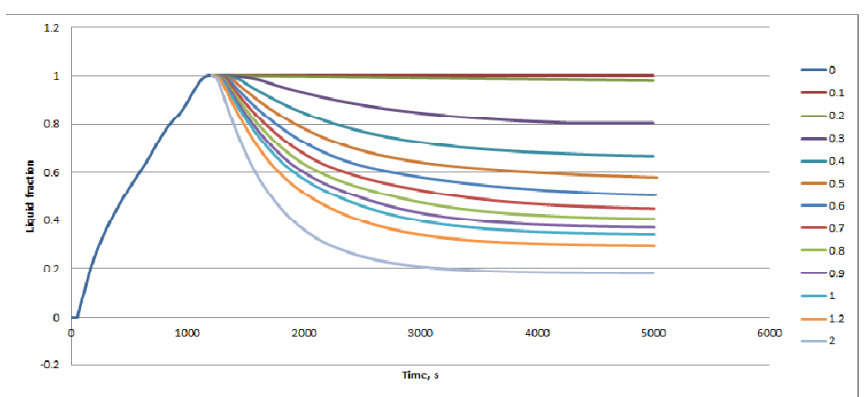

Liquid fraction in PCM region with time for different inlet velocity $(\mathrm{m} / \mathrm{s})$ 


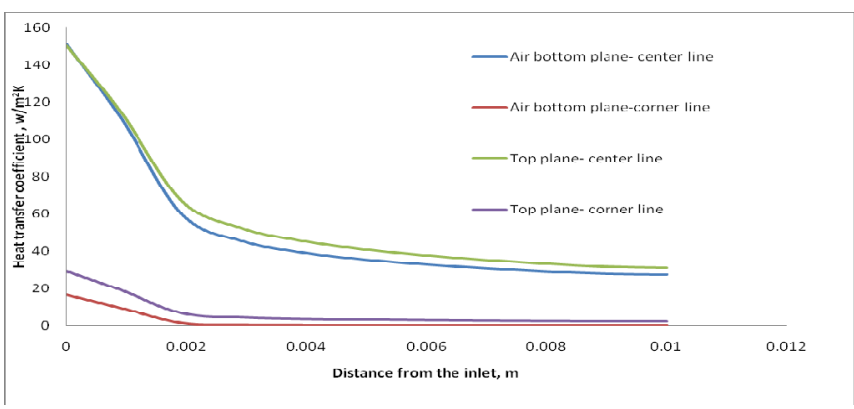

Heat transfer coefficient along the flow direction for an inlet velocity of $1 \mathrm{~m} / \mathrm{s}$

Heat transfer coefficient along axial distance at different locations is depictured in figure 5.16. The heat transfer coefficient at center location of the air flow passage is higher than the corner locations. The top air PCM interface is having higher than the bottom air fin interface. This is due to difference in temperature gradients in corresponding locations

Time requirement for solidification for different inlet velocities

\begin{tabular}{|c|c|c|c|c|c|c|}
\hline $\begin{array}{c}\mathbf{L F} \\
\mathbf{\%}\end{array}$ & $\begin{array}{c}\mathbf{0 . 8} \\
\mathbf{m} / \mathbf{s}\end{array}$ & $\begin{array}{c}\mathbf{1 . 0} \\
\mathbf{m} / \mathbf{s}\end{array}$ & $\begin{array}{c}\mathbf{1 . 2} \mathbf{m} / \mathbf{s} \\
\mathbf{2 0}\end{array}$ & $-\begin{array}{c}\mathbf{1 . 4} \\
\mathbf{m} / \mathbf{s}\end{array}$ & $\begin{array}{c}\mathbf{1 . 6} \\
\mathbf{m} / \mathbf{s}\end{array}$ & $\begin{array}{c}\mathbf{2 . 0} \\
\mathbf{m} / \mathbf{s}\end{array}$ \\
\hline $\mathbf{3 0}$ & - & - & - & - & $\begin{array}{c}380 \\
0\end{array}$ & $\begin{array}{c}200 \\
0\end{array}$ \\
\hline $\mathbf{4 0}$ & $\begin{array}{c}380 \\
0\end{array}$ & $\begin{array}{c}180 \\
0\end{array}$ & $\begin{array}{c}130 \\
0\end{array}$ & $\begin{array}{c}102 \\
0\end{array}$ & $\begin{array}{c}140 \\
0\end{array}$ & $\begin{array}{c}100 \\
0\end{array}$ \\
\hline $\mathbf{5 0}$ & $\begin{array}{c}150 \\
0\end{array}$ & $\begin{array}{c}105 \\
0\end{array}$ & 830 & 700 & 630 & 500 \\
\hline
\end{tabular}

The time requirement for control the temperature of the PCM to various liquid fraction levels for different air inlet velocity is listed in the Table 4. Based on the usage of the device the air flow velocity can be varied as per the requirements. From the tabulated results it is clear that to obtain a liquid fraction of $20 \%$ it is necessary to set a minimum air velocity of $1.6 \mathrm{~m} / \mathrm{s}$ similarly for $30 \%$ liquid fraction is $1.2 \mathrm{~m} / \mathrm{s}$. Increasing velocity above $1.6 \mathrm{~m} / \mathrm{s}$ gives only small improvement in performance. Hence these results can be used as easy-to-use design guidance line for PCM based heat sinks, in terms of forced convective conditions.

\section{CONCLUSIONS}

The PCM based cooling techniques have great potential application in electronic devices. In this work study and analysis of PCM based heat sinks is carried out. Numerical analysis is done by using FLUENT 14.0. The works includes the study on characteristics of PCM and its application is carried out. Here we conducted three configuration of heat sinks such as fin only, fin filled with PCM material, fin with half-filled PCM .The characteristics of Heat sink with PCM is analysed in both solidification and melting process and find out the time in which PCM controls temperature up to 2400s for full filled PCM. For continuous application the forced air convection is included in the analysis by changing half portion of PCM to air domain. The maximum temperature/ liquid fraction/ heat transfer coefficient at different locations are obtained for different velocity is computed in the steady state analysis. Performance of heat sink for continuous operation is carried out for different air flow conditions. The unsteady analysis for studying the transient nature of problems. The time requirements for control the temperature of PCM to various liquid fraction levels for different forced convection conditions are tabulated, which can be used as easy-to-use design guide line for PCM based heat sink.

\section{REFERENCES}

[1] V. Shatikian, G. Ziskind, R. Letan, Numerical investigation of a PCM-based heat sink with internal fins, International Journal of Heat Mass Transfer 48, 36893706, 2005

[2] V.Dubovsky,E.Assis,E.kochavi,G.Ziskind and R.Letan,Study of solidification in vertical cylindrical shells, International Communications in Heat and Mass Transfer 34 (2007) 62-71

[3] Gong andArun.S. Mujumdar, A transient cooling of electronics using phase change materials,ASME Journal of Solar Energy Engineering 117, 215-220, 1995.

[4] Bogdan M. Diaconu ${ }^{\mathrm{a}, \mathrm{b}}$,, SzabolcsVarga ${ }^{\mathrm{a}}$, Armando C. Oliveira ${ }^{a}$ Experimental assessment of heat storage properties and heat transfer characteristics of a phase change material slurry for air conditioning applications, Applied Energy 87 (2010) 620-628

[5] X. Duan, G.F. Naterer, Heat transfer in phase change materials for thermal management of electric vehicle battery modules, Department of Nuclear Science and Engineering, Massachusetts Institute of Technology, 77 Massachusetts Avenue, Cambridge, MA 02139, USA, Faculty of Engineering and Applied Science, University of Ontario Institute of Technology, 2000 Simcoe Street North, Oshawa, Ontario, Canada.

[6] QIU Yifena, JIANG Nanb, WU Weia, ZHANG Guangweia, Heat Transfer of Heat Sinking Vest with Phase-change Material, China Aerospace Life-support Industries, Ltd., 2011.

[7] PaisarnNaphon, Laminar convective heat transfer and pressure drop in the corrugated channels, International Communications in Heat and Mass Transfer 34 (2007) $62-71$

[8] Mónica Delgado*, Ana Lázaro, Javier Mazo, José MaríaMarín, BelénZalba, Experimental analysis of a microencapsulated PCM slurry as thermal storage system 
and as heat transfer fluid in laminar flow, Applied Thermal Engineering 36 (2012) 370-377

[9] Mohammad M. Mansoor , Kok-Cheong Wong , MansoorSiddique, Numerical investigation of fluid flow and heat transfer under high heat flux using rectangular micro-channels,International Communications in Heat and Mass Transfer 39 (2012) 291-297

[10] S V. Garimella, A Novel Hybrid Heat Sink using Phase Change Materials for Transient Thermal Management of Electronics, (2005). CTRC Research Publications. Paper 66.

[11] R. Kandasamy, X.Q. Wang, A.S. Mujumdar, Application of phase change materials in thermal management of electronics, Applied Thermal Engineering, in press, 2006.

[12] B. Zalba, J.M. Marin, L.F. Cabeza, H. Mehlin, Freecooling of building with phase change materials, International Journal of Refrigeration 27 (2004) 839-849.

[13] S. Krishnan, S. Garimella, S. Kang, A novel hybrid heat sink using phase change materials for transient thermal management of electronics, in: Proceedings of 2004 Inter Society Conference on Thermal Phenomena (ITHER M04), 2004, pp. 310-318.

[14] X.-Q. Wang, C. Yap, A.S. Mujumdar, Cyclic melting and freezingheat transfer using paired phase change materials, in: B. Thorat, S. Devahastin, G. Chen (Eds.), Topics Heat and Mass Transfer, 2004.

[15] R. Akhilesh, A. Narasimhan, C. Balaji, Method to improve geometry for heat transfer enhancement in PCM composite heat sinks, International Journal of Heat and Mass Transfer 48 (13) (2005) 2759-2770.

[16] A.Brent, V.Voller, K. Reid, Enthalpy-porosity technique for modeling convection diffusion phase change: application to the melting of a pure metal, Numerical Heat Transfer, Part A 13 (1988) 297-318.

[17] R. Reid, J. Prausnitz, B. Poling, The Properties of Gases and Liquids, McGraw-Hill, New York, 1987.

[18] Inaba $\mathrm{H}$, Zhang $\mathrm{Y}$, Horibe A. Numerical simulation of natural convection of latent heat phase-change-material mico capsulate slurry packed in a horizontal rectangular enclosure heated from below and cooled from above. Heat Mass Trans 2007; 43:459-70.

[19] Bhattacharya M, Basak T, Ayappa K G. A fixed-grid finite element based enthalpy formulation for generalized phase change problems: role of superficial mushy region. International Journal of Heat and Mass Transfer 2002, 45(24): 4881-4898.

[20] Voller V R. Fast implicit finite-difference method for the analysis of phase change problems. Numerical HeatTransfer Part B: Fundamental 1990, 17(2): 155-169.

[21] ZengY, Tian H Z, Yu P, et al. The study on effective heat transfer coefficient in the math model of energy storage system with solid-liquid phase change by theoryand experiments. Fluid Machinery 2002, 30(6): 44-48.

[22] Costa M, Buddhi D, Oliva A. Numerical simulation of a latent heat thermal energy storage system with enhanced heat conduction. Energy Conversion \& Management 1998, 39(3-4): 319-330.

[23] Voller V R. Fast implicit finite-difference method for the analysis of phase change problems. Numerical Heat Transfer Part B: Fundamental 1990, 17(2): 155-169. 